\title{
Trabalhadores do batuque: a carreira numa religião afro-gaúcha
}

\author{
Alexandre Dal Molin Wissmann ${ }^{1}$ \\ JHONY PEREIRA MORAES ${ }^{1}$ \\ ARTHUR GEHRKE MARTINS ANDRADE ${ }^{1}$ \\ JAIR JEREMIAS JUNIOR ${ }^{1}$
}

${ }^{1}$ Universidade federal do Rio Grande do Sul (UfrgS) / Programa de Pós-Graduação em Administração, Porto Alegre - RS, Brasil

\section{Resumo}

Analisando a relação tempo-espaço e suas transformações longitudinais, bem como as dinâmicas objetivas e subjetivas entre sujeito e contexto, este trabalho tem como objetivo investigar a carreira no batuque de 2 pessoas de diferentes gerações que vivem essa trajetória. Para isso, resgatamos a construção histórica da ocupação e utilizamos o conceito de carreira para fundamentar a pesquisa. Como método de investigação, usamos a história de vida. Os resultados apontam para mudanças transcorridas na carreira, vistas ao nível individual pelas reinterpretações dos entrevistados e ao nível estrutural e contextual pelas reconfigurações dos atores presentes no campo. Também foi possível, diante da perspectiva de tempo, identificar elementos antecedentes, distintos, presentes e comuns aos sujeitos envolvidos, assim como visualizar indícios de mudanças no campo dessa carreira. Além da investigação sobre a ocupação do batuque, o trabalho apresenta as diferenças oriundas do tempo e do espaço, em instituições, grupos e indivíduos, baseado na visualização da carreira de 2 pessoas de diferentes gerações que trilharam caminhos nesse campo.

Palavras-chave: Carreira. Batuque. Religião afro-gaúcha. História de vida.

\section{Batuque workers: career in an afro-gaúcha religion}

\begin{abstract}
This study investigated the career of two people from different generations to analyze the time-space relationship and its longitudinal transformations, and the objective and subjective dynamics existing between subject and context. We used the historical construction of the occupation and the concept of career to support the research. As a research method we use life story. The results show the changes that have taken place in careers at an individual level through the reinterpretations of the interviewees and at a structural and contextual level through the reconfigurations of the actors present in the field. It was also possible, from the perspective of time, to identify antecedent, distinct, present, and common elements of the subjects involved, and signs of changes in the field of this career. In addition to investigating the occupation of batuque, this work presents the differences arising from time and space, in the context, institutions, groups, and individuals, from the visualization of the careers of two people of different generations.
\end{abstract}

Keywords: Career. Batuque. Afro-gaúcha religion. Life story.

\section{Trabajadores del batuque: la carrera en una religión afrobrasileña}

\section{Resumen}

Analizando la relación tiempo-espacio y sus transformaciones longitudinales, así como las dinámicas objetiva y subjetiva existentes entre sujeto y contexto, este estudio tuvo como objetivo investigar la carrera en la religión batuque de dos personas de diferentes generaciones. Para ello, rescatamos la construcción histórica de la ocupación y utilizamos el concepto de carrera para sustentar la investigación. Como método de investigación utilizamos la historia de vida. Los resultados muestran los cambios que se han producido en la carrera, vistos a nivel individual por las reinterpretaciones de los entrevistados y a nivel estructural y contextual por las reconfiguraciones de los actores presentes en el campo. También fue posible, desde la perspectiva del tiempo, identificar elementos antecedentes, distintos, presentes y comunes a los sujetos involucrados, así como ver señales de cambios en el campo de esta carrera. Además de investigar sobre el trabajo en el batuque, la obra contribuye presentando las diferencias que surgen del tiempo y el espacio, en el contexto, instituciones, grupos e individuos, a partir de la visualización de las trayectorias de dos personas de distintas generaciones que han transitado caminos en este campo.

Palabras clave: Carrera. Batuque. Religión afrobrasileña. Historia de vida. 


\section{INTRODUÇÃO}

Diante de seu caráter processual, histórico e contextual, o conceito de carreira permite observar, com base na trajetória de pessoas, um quadro amplo, integrando sujeitos, coletividades, organizações e sociedade, retratando as interações recíprocas existentes sob uma perspectiva longitudinal e territorial (Hughes, 1958; Mayrhofer, Meyer \& Steyrer, 2012). Além disso, a concepção de carreira oferece a possibilidade de pesquisa de ocupações não tradicionais e pouco exploradas (Becker, 2008; Hughes, 1937).

Ao passo que nos afastamos de carreiras convencionais, é importante lembrar que, quando nos deparamos com ambientes, culturas ou crenças distantes de nossos espaços tradicionais, nos colocamos diante de novas palavras, costumes e significados, os quais, por sua vez, nos fazem reinterpretar e criar novos entendimentos sobre aquilo já construído. É nessa óptica que alicerçamos o presente estudo, tratando de uma carreira periférica e entreposta numa religião distante das correntes populares. Trata-se do batuque, uma religião pouco conhecida nacionalmente e disposta, para um grupo de pessoas, também como uma ocupação.

Essa vertente é considerada uma religião afro-gaúcha em função de suas raízes africanas e de seu processo histórico de formação e sincretismo no Rio Grande do Sul (Corrêa, 2006). Hoje, com mais de 200 anos de história em solo gaúcho e espalhada também pelos Países do Prata - Uruguai, Argentina e Paraguai -, ela parece ter criado um complexo campo de relações em que estão inseridos pais e mães de santo, fiéis, associações representativas, entidades públicas, fabricantes e comerciantes de produtos religiosos, além de clientes e entidades de outras vertentes religiosas (Leistner, 2016; Oro, 1998).

Para além dos números, que apontam o Rio Grande do Sul como o estado brasileiro onde há o maior número de pessoas declaradas pertencentes a religiões afro-brasileiras (Instituto Brasileiro de Geografia e Estatística [IBGE], 2019), as práticas e os movimentos dentro do campo religioso vêm assumindo novas formas e buscando se modernizar diante das transformações contextuais (Oro, 2012). Seja pelo viés da religião, seja pela perspectiva de trabalho, é este o quadro - de movimentações e transformações - que configura o campo do batuque.

Analisando a relação tempo-espaço e suas transformações longitudinais, bem como as dinâmicas objetivas e subjetivas entre sujeito e contexto, este trabalho se propõe a investigar a carreira no batuque com base na narrativa de 2 pessoas de diferentes gerações que vivem essa trajetória. Partindo de um ponto de vista interacionista, considerando que as carreiras se estruturam sob objetividades e subjetividades, conflitos e dilemas, bem como elucidam relações entre indivíduos e instituições (Hughes, 1937), o interesse na investigação acerca do campo do batuque reforça o entendimento de que todos fazem e têm uma carreira, independentemente da estrutura a que estejam vinculados, percorrendo diferentes caminhos e tomando decisões num ambiente de contingências.

Para isso, com base no quadro conceitual de carreira, buscamos resgatar a história dessa ocupação e dos sujeitos da pesquisa, contextualizando e interpretando ações, assim como identificando o papel de pessoas, grupos, organizações e sociedade nesse meio.

Diante de tal proposta, além desta introdução, na qual se apresenta o tema central e se explicita o objetivo, o trabalho se divide em 6 partes. A primeira se dedica a uma discussão sobre o conceito de carreira, abordando as contribuições da concepção teórica e os elementos que embasaram o trabalho. Em seguida, promove-se uma retomada histórica do campo no qual está inserida a trajetória da ocupação, apontando suas transformações e retratando sua atual conjuntura. Os aspectos metodológicos são apontados na terceira seção, e, na quarta, se analisam as narrativas dos entrevistados, retratando suas carreiras. Na parte subsequente, empreende-se a discussão dos dados à luz da base teórica. Por fim, apresentam-se as considerações finais do estudo. 


\section{CARREIRA E DESVIO}

O conceito de carreira permite às pesquisas reunir pessoas, grupos, organizações e sociedade dentro de uma investigação. Sua constituição teórica interdisciplinar oferece um campo de análise em que estão presentes elementos como o tempo e a construção histórica do espaço social, os elementos objetivos e subjetivos e as interações entre os envolvidos (Moore, Gunz \& Hall, 2007). Em conjunto, essa concepção proporciona a exploração de grupos sociais periféricos e novos contextos (Hughes, 1937).

A noção de tempo oferecida pela base teórica de carreira permite observar diferentes retratos relacionados ao objeto de estudo e suas transformações ao longo do tempo (Hughes, 1937). Isso quer dizer que é possível examinar cenários do passado, transfigurações ocorridas, retratar o presente contexto e até projetar quadros futuros referentes à carreira. Além disso, a investigação da história de um campo no qual a carreira está disposta reflete a construção do espaço social em que pessoas, organizações e sociedade estão inseridas.

Assim, a carreira se apresenta como algo que abarca todas as esferas da vida do indivíduo (Hughes, 1958), o que permite identificar 2 esferas correlacionadas. A primeira são construções e transformações objetivas que se entrelaçam com a carreira, individualmente ou em grupos, organizações ou sociedade. A segunda são as construções subjetivas da pessoa, a forma como ela observa e avalia seu mundo, criadas com base em suas relações contextuais e objetos de constante ressignificação. Esse quadro conceitual gera um cenário relacional, interacional e contextual de análise (DeLuca \& Rocha-de-Oliveira, 2016).

A perspectiva relacional do conceito de carreira proporciona que todos os níveis de análise e os elementos presentes na discussão sejam envolvidos (Arthur, Hall \& Lawrence, 1989). Isso possibilita uma análise da dinâmica entre indivíduos, organizações, instituições e sociedade. Por outro lado, abrem-se caminhos para a associação entre elementos objetivos e subjetivos de carreira, que, por sua vez, também podem ser vistos de forma longitudinal, observando a natureza dessas relações ao longo do tempo.

Em meio a tal quadro de análise das carreiras, na busca pela compreensão das interações sociais, o indivíduo tem papel central ao refletir tais dinâmicas por meio de suas percepções (Carter \& Fuller, 2016). No entanto, é importante observar essas dinâmicas como uma via de mão dupla, em que indivíduos influenciam e são influenciados pelas instituições de seu espaço (Hughes, 1958). Nesse caso, reforçamos a importância de contextualizar o espaço da carreira, uma vez que os movimentos da trajetória são influenciados pela localização territorial do campo e por seus aspectos sociais e culturais (Abbott, 1997; Hughes, 1937).

Vinculadas ao contexto e às suas representações, as carreiras desviantes refletem trajetórias de pessoas em carreiras em áreas não tradicionais e que pertencem a subgrupos sociais. Embora o termo seja relativo, sua importância reside na compreensão da construção desse rótulo no contexto da pessoa, ou seja, um "comportamento desviante é aquele que as pessoas rotulam como tal” (Becker, 2008, p. 22).

As carreiras desviantes podem ser reconhecidas no momento em que a pessoa quebra o padrão socialmente estabelecido e se desvincula de padrões e normas historicamente vistos como tradicionais. Seguindo esse caminho e inserida em grupos periféricos, a pessoa é vista como desviante, assim como sua carreira. Em paralelo, e adentrando o mundo do batuque, Frigerio (2008) sugere que adeptos de religiões consideradas não tradicionais podem receber o mesmo status: desviante.

\section{DO BATUQUE À LINHA CRUZADA: TRANSFORMAÇÕES E O CENÁRIO ATUAL DO CAMPO}

Embora não existam informações concretas sobre o surgimento das religiões de origem africana no Rio Grande do Sul, acredita-se que suas primeiras expressões tenham ocorrido entre o fim do século XVIII e o início do século XIX. Neste momento, Corrêa (2006) rememora que as cidades de Rio Grande e Pelotas recebiam grande número de escravos para trabalhar nas charqueadas e que estes, conforme se estabeleciam, semeavam seus traços identitários na região. É importante notar como o contexto e o avanço temporal foram determinantes para a estruturação dessas religiões e de suas práticas. Em diversas pesquisas, percebe-se como as religiões de matriz africana foram se adaptando às condições socioculturais e econômicas do Rio Grande do Sul (Oro, 2002; Tadvald, 2016). 
A primeira religião de origem africana que se manifestou no estado foi o batuque. Sua adaptação foi rápida, de modo que os costumes tradicionais do território se assemelhavam às práticas da religião. Além disso, as características da época facilitaram a execução das ações. A estrutura patriarcal dos orixás cultuados se identificava com a das famílias. Os animais que perambulavam tranquilamente pelas ruas da cidade facilitavam a execução dos rituais de sacrifício. Por fim, as relações de trabalho quase inexistentes e o distanciamento espacial entre as residências possibilitavam os cultos prolongados e o som dos tambores durante as madrugadas (Corrêa, 2006).

Só na década de 1930, diante de um cenário um tanto diferente, é que a segunda vertente afro-brasileira começou a ser observada em solo gaúcho. Surgia a umbanda. De acordo com Oro (2002), suas práticas vinham na contramão do batuque, buscando se acomodar a um cenário de crescimento das cidades, aglomeração das moradias e início do processo de industrialização. Com esse quadro, em que ao trabalho se conferia maior importância e no qual o ritmo das cidades se tornava acelerado, a umbanda exigia menores compromissos de seus fiéis, tinha reuniões mais curtas e sem o barulho de tambores, visando não atrapalhar os vizinhos ou não chamar sua atenção. Além disto, não se praticava o sacrifício de animais, uma vez que estes se tornavam mercadorias valiosas (Oro, 2002).

A última corrente afro-brasileira a surgir no Rio Grande do Sul foi a linha cruzada. Corrêa (2006) indica que seu surgimento ocorreu no fim da década de 1960, em paralelo com a consolidação do capitalismo e de problemas como desemprego, insegurança, doenças e frustrações. Ajustando-se ao contexto, a linha cruzada se desenvolveu de uma mescla de práticas do batuque, da umbanda e de outras religiões, sendo definida como uma "religião prática, pragmática, de serviço, que se especializa nas soluções sobrenaturais" dos problemas enfrentados pelo homem moderno (Oro, 2002, p. 359). É essa vertente, de natureza híbrida e adaptativa, que mais se espraiou nesse espaço. Os últimos registros mostram que, em Porto Alegre, cerca de 95\% dos terreiros - num universo de 2 mil - cultivam as práticas da linha cruzada (Corrêa, 1994).

Hoje, sob a esteira do regime capitalista, as religiões de origem africana, além de estarem se transformando em consumo, figuram como peças centrais de um cenário complexo (Prandi, 1996). Em solo gaúcho, em especial na região de Porto Alegre, é visível a estruturação de um mercado próprio das religiões. Num dos tópicos de sua pesquisa, Oro (1998) disserta sobre o impacto da economia nas religiões afro-gaúchas e retrata o envolvimento entre agentes, instituições e empresas nesse espaço. Ao contrário de outrora, hoje, além de o cenário ser composto por um número maior de atores, estes desempenham papéis distintos e complexos. Tendo em vista a análise do campo no qual está inserida a carreira do batuque, é importante apontar a presença destes atores - pessoas, grupos, organizações e sociedade - e oferecer características de sua atuação no território analisado.

Levando em consideração os objetivos deste estudo, estão no cerne da análise uma mãe e um pai de santo, figuras complexas nesse campo de investigação. Sob a óptica religiosa, representam a peça central e a autoridade máxima do terreiro ou da casa de religião. Na esfera do trabalho, são prestadores informais de serviço, sendo considerados, muitas vezes, pequenos empreendedores, os quais, a despeito de desempenharem a função de sacerdotes, precisam "constituir um fundo econômico capaz de garantir a infraestrutura e o funcionamento do terreiro, além do seu próprio sustento e o de sua família" (Oro, 1998, p. 8).

Essas 2 faces da ocupação nos levam a outros 2 componentes do campo: os fiéis e os clientes, distintos em função do vínculo com a religião. Os primeiros carregam em sua identidade todo o conteúdo que circunda a esfera religiosa, enquanto aos clientes a religião é vista como um serviço capaz de atender às suas necessidades de ordem emocional ou econômica (Prandi, 1996).

Também fazem parte dessa conjetura as indústrias e os estabelecimentos que comercializam os bens de consumo, como velas, estátuas, ervas e floras, utilizados em práticas e rituais desse grupo social (Giorgio, 2015). A presença de tais agentes demarca a transformação da lógica de trabalho dessas pessoas, uma vez que, antes, os materiais utilizados eram cultivados pelos próprios sujeitos e, agora, se configuram como custos embutidos no valor dos serviços prestados.

As entidades representativas - com destaque no Rio Grande do Sul para a Federação das Religiões Afro-Brasileiras (Afrobras) e a Federação Afro-Umbandista Espiritualista do Rio Grande do Sul (Fauers) - também são instituições ativas no campo da carreira dessa ocupação. Conquanto as ações dessas entidades girem em torno de várias demandas desse conjunto social, suas atuações se destacam pela defesa do grupo diante de atos discriminatórios. 
Isso nos leva a destacar a presença das instituições e de fiéis de diferentes crenças, que, de formas distintas, se relacionam com as religiões afrodescendentes. Nessa esfera, é preciso enfatizar o papel das igrejas pentecostais - vertente religiosa evangélica que chegou ao Brasil na década de 1960 e que hoje é representada pelo neopentecostalismo, sobretudo pela Igreja Universal do Reino de Deus (lurd), de Edir Macedo - que assumiram a proa das ações discriminatórias contra as expressões religiosas de matriz africana no Brasil, sob o argumento de que estas cultuam demônios em suas práticas (Souza, 2019).

Há também que considerar na análise o papel do Estado e da sociedade local. Em relação ao primeiro, suas ações podem ser vistas em Porto Alegre, principalmente por meio da Secretaria Adjunta do Povo Negro, da prefeitura, e pelas discussões sistemáticas no interior do sistema legislativo de assuntos conflitantes sobre as práticas religiosas afro-gaúchas (Prefeitura Municipal de Porto Alegre, 2019). É possível citar a discussão referente ao sacrifício de animais nas práticas religiosas africanistas e a emenda que proíbe o abandono de animais mortos em vias públicas no Rio Grande do Sul (Leistner, 2016; Oro, Carvalho \& Scuro, 2017). Quanto ao espaço e à sociedade local que cercam as carreiras em questão e onde todas as interações se desenrolam, temos o Rio Grande do Sul, que - ainda que busque criar uma autoimagem de ser constituído por pessoas brancas, cristãs, colonizado e habitado por imigrantes europeus - guarda em sua história e conserva os traços da bagagem de índios e negros (Oliven, 2006).

É nesse campo que pais e mães de santo - figuras que, ao mesmo tempo, são sacerdotes e prestadores de serviços, vistos por uns como a alma de um terreiro e por outros como demônios que devem ser exorcizados - vivem suas trajetórias. É nessa ocupação, um tanto contraditória, envolta por relacionamentos complexos e intercambiando elementos com múltiplos atores, que se abrem espaços e caminhos para a investigação.

\section{METODOLOGIA}

Diante das características do campo de trabalho dos entrevistados, do objetivo proposto e da base teórica sobre carreira, utilizamos a estratégia da história de vida como método, buscando compreender a trajetória do sujeito com base em sua própria narrativa. As histórias de vida são uma escolha metodológica em que geralmente são colocados em relevo sujeitos em posições profissionais em desaparecimento ou invisibilidade, mulheres e grupos étnicos e socioculturais discriminados em territórios periféricos (Fernandes, 2010). Para o campo da administração, sobretudo, para os estudos que evidenciam discussões sobre carreira, o método de história de vida se mostra oportuno, pois se revela um caminho metodológico em potencial para as investigações (Closs \& Rocha-de-Oliveira, 2015).

O método história de vida surge com a Escola de Chicago, no início do século XX, nos Estados Unidos. Foi a partir dos anos 1970 que o método tomou proporções maiores, partindo de uma simples coleção de dados empíricos, numa perspectiva positivista, para o conhecimento sobre indivíduos e grupos, suas experiências históricas e singulares. Assim, passou a aprofundar a compreensão e a captação das mensagens originárias nas histórias desses grupos. Para tanto, ampara-se em testemunhos, visando à reconstrução da história dos sujeitos desde sua infância até o presente. Pelas histórias de vida, os sujeitos são "textos vivos", se assim se pode dizer, uma vez que reconstroem seu passado e projetam o futuro para além do tempo presente, agregando novos significados e transformando sua existência (Granato, Lopes \& Costa, 2020).

Nas histórias de vida, há uma relação igualitária entre pesquisador e pesquisado. Tende-se a desenvolver vínculos recíprocos de confiança, envolvimento e compromisso, em especial por parte do investigador. Diz-se, de igual modo, que ambas as partes se transformam ao longo do processo, isto é, pesquisado e pesquisador são objetos e sujeitos da investigação. Outra característica do método é sua historicidade. Ou seja, ele permite a análise e a compreensão de elementos que formam o sujeito, reconstruindo sua relação com a história (sujeito histórico), pois ele é, simultaneamente, produto e produtor dela (Granato et al., 2020).

Esta pesquisa também se apoia na análise das trajetórias de vida para a compreensão de interações e sequenciamento entre as gerações. Sob essa abordagem, a percepção de indivíduos de diferentes gerações pode mostrar traços similares e contrastes entre trajetórias (Atkinson, 2002; Brandão, 2007). 
Como método complementar, optou-se pela utilização da análise de conteúdo qualitativa, tida por Bardin (2010) como um conjunto de técnicas de análise das comunicações que utiliza procedimentos sistemáticos e objetivos de descrição do conteúdo das mensagens, com intenção de inferência de conhecimentos relativos às condições de produção. A análise pode ser quantitativa e qualitativa, sendo que a abordagem quantitativa traça uma frequência das características que se repetem no conteúdo do texto e a qualitativa considera a presença ou a ausência de dada característica de conteúdo ou conjunto de características em determinado fragmento da mensagem (Caregnato \& Mutti, 2006).

A utilização, tanto da estratégia de história de vida quanto da análise de conteúdo, deve se adequar ao campo e aos objetivos pretendidos, tratando-se, portanto, de opção dos pesquisadores pela combinação dessas 2 metodologias, com vistas a obter inferências de aspectos objetivos e subjetivos, considerando elementos contextuais, institucionais, de identidade e status, visto que o significado e o sentido utilizados na narrativa estão intimamente relacionados às interações sociais nas quais estão envolvidos, as quais podem sofrer alterações ao longo do tempo e propiciar reinterpretações do passado no presente (Bujold, 2004).

Nesse passo, a primeira etapa do estudo se voltou para a pesquisa exploratória, em que foram recolhidos dados de fontes secundárias acerca dos 2 principais tópicos tratados na fundamentação teórica: carreira e campo do batuque. A análise bibliográfica contemplou também um aprofundamento histórico, sobretudo do campo no qual a religião do batuque se desenvolveu, visando o entrelaçamento entre o tempo e o espaço na narrativa dos sujeitos.

Os encontros com os entrevistados e a observação do campo representaram a segunda etapa da pesquisa. Nessa fase, foram realizados 3 encontros com Aparecida e Wesley, mãe e filho, ambos batuqueiros e moradores de Porto Alegre. Cada encontro durou cerca de 2 horas, e, a pedido de Aparecida, ocorreram em conjunto, participando dos momentos 1 dos pesquisadores e os 2 entrevistados. As conversas ocorreram na residência da família, espaço onde também funciona o centro de religião do qual são proprietários. O local, dividido em 3 ambientes, merece destaque. O primeiro, junto à calçada, é destinado às sessões da família religiosa de ambos. O segundo é privado e destinado a conversas particulares entre Aparecida ou Wesley e seus clientes. $O$ terceiro fica ao fundo do terreno e é onde se localizam todos os demais cômodos da casa.

Além desses momentos, mais uma visita foi realizada ao centro de religião. Nessa oportunidade, pessoas ligadas à família religiosa de ambos os entrevistados estavam presentes. O objetivo era compreender a dinâmica e os processos de trabalho realizados, bem como se aproximar do dialeto e do sistema de códigos e símbolos do universo em questão. As percepções durante todos os encontros foram registradas em diários de campo que permitiram o aprofundamento analítico do estudo.

Ressaltamos que, ao fim de cada encontro, os diálogos eram transcritos e uma análise prévia era empreendida com base em tais registros e nos diários de campo, em busca de pontos que mereciam maior atenção para que pudessem ser novamente abordados no encontro subsequente. Após o processo de transcrição dos diálogos do último encontro, deu-se início à análise das narrativas, levando em consideração que contar uma história de vida é retratar, ao mesmo tempo, múltiplas histórias (Vogt \& Bulgacov, 2019). Por meio delas, é possível vislumbrar significados e experiências - subjetivamente interpretados por quem ouve - que, à medida que desvelam a individualidade de uma pessoa, refletem a sociedade, iluminando seus valores socioculturais, seu percurso histórico e econômico e as instituições que dela fazem parte (Colling \& Oltramari, 2019).

Entendendo a vida como uma construção social, compreendemos aspectos objetivos e subjetivos. A análise, objetivamente, pode investigar questões de ordem econômica, política, histórica e social, ao passo que, subjetivamente, tem o poder de verificar construções sociais e emoções próprias do sujeito, arquitetadas temporalmente e dentro de um campo específico (Closs \& Rocha-de-Oliveira, 2015). 


\section{UMA CARREIRA, DUAS GERAÇÕES E MÚLTIPLOS CONTRASTES}

Esta seção apresenta a trajetória de vida, primeiro de Aparecida e, posteriormente, de Wesley. Com a análise da carreira dos entrevistados, buscamos apontar suas características e traçar paralelos que mostram elementos comuns e, ao mesmo tempo, indicam diferenças significativas tanto para as construções individuais dessas pessoas quanto de maneira ampla, observando as transformações coletivas e institucionais relacionadas à carreira no batuque.

\section{De Aparecida à Cidinha da Oiá}

Com nome da rainha e padroeira do Brasil, Aparecida nasceu no fim da década de 1960, no interior do Rio Grande do Sul, numa cidade distante da capital gaúcha, chamada Jaguari. O município, à época, tinha cerca de 10 mil habitantes e uma população baseada em imigrantes europeus, entre os quais o cristianismo predominava desde sua formação (Ferreira, 1959). Sua família, de origem simples, vivia em consonância com os costumes da comunidade, o que a fez vivenciar experiências desde sua infância no mundo católico.

Aos 7 anos, recebeu a notícia da avó de que os pais haviam ido embora da cidade. Hoje, ela entende e explica a complexa situação, revelando que, na época, a pequena cidade, fervorosamente católica e adentrando um período de ditadura militar, repreendeu e afugentou sua mãe, que começara a receber uma entidade espiritual, algo estranho aos olhos da comunidade.

Após alguns meses morando com a avó, mudou-se para Santa Maria, novamente junto dos pais. Ao chegar, Aparecida relembra que estava diante de um novo mundo. Numa cidade maior e enfrentando resistências tradicionais menores, sua mãe se distanciou do catolicismo e estava imersa na religião do batuque. Trabalhando e vivendo a religião intensamente, ela, além de seguidores, já tinha um centro de religião, onde transcorriam as atividades.

Nesse momento, sua mãe começou a formar a própria família religiosa, composta por seguidores, orixás e entidades. Tomada pelas atividades dessa outra família, sua mãe se afastou dos afazeres domésticos e maternais, indo na contramão das expectativas do marido. Em seguida, seus pais acabaram se separando. A entrevistada, ainda criança, herdou as responsabilidades domésticas e os cuidados com os 4 irmãos mais novos, marcando uma ressignificação de seu "papel" social de criança.

Mesmo que a cidade tivesse mais habitantes e a sensação de liberdade se mostrasse maior, religiões não tradicionais ainda eram crivadas de desconfiança pelos moradores, sobretudo pelas autoridades locais. O período, marcado pela ditadura, carregava uma série de restrições. Aparecida recorda que, para realizar suas atividades e não ser vista, a mãe trabalhava nas madrugadas. Relembra ainda que a mãe foi presa várias vezes enquanto trabalhava em esquinas, em matos ou tocando tambor na beirada dos rios, práticas comuns na atividade.

Em meio a esse contexto, Aparecida adentrava o universo religioso e, ainda na primeira década de sua história, viveu a primeira experiência espiritual, incorporando uma entidade: a cabocla Jurema. Após essa experiência, a mãe limitou sua presença nas sessões, mostrando-se contrária à sua participação. O desejo dela era que a filha apenas estudasse e não participasse profundamente das atividades religiosas, entendendo a hostilidade do período. Nesse momento, Aparecida se distanciou parcialmente da religião. A congregação do abandono temporário dos pais, a separação deles, as responsabilidades domésticas e com os irmãos, a violência contra a mãe no período da ditadura militar e o posicionamento contrário dela a afastaram desse universo.

A partir desse ponto, a entrevistada considera ter percorrido uma vida normal: estudou até a quarta série do ensino fundamental e morou em diferentes cidades junto com a mãe até fixarem residência em Porto Alegre. Na capital gaúcha, Aparecida se casou, teve o único filho e trabalhou em vários lugares, com funções diferentes no decorrer dos anos. A não permanência por longos períodos nas funções permitiu que experimentasse diversas ocupações em suas 3 primeiras décadas de vida, passando por atividades industriais em linhas de produção, tarefas administrativas e até como pequena empreendedora. No entanto, Aparecida afirma que não houve identificação com nenhum ofício desempenhado.

Até os 30 anos, embora não recebesse sua entidade, a religião a rodeava de outras maneiras. Esporadicamente, participava de sessões, tomava passes para descarrego, observava o trabalho da mãe e, de modo informal, quase como uma brincadeira, como relata, jogava cartas para as amigas. Esse cenário, porém, começou a mudar quando o marido foi diagnosticado com uma grave doença que impactou - econômica e emocionalmente - a família durante alguns anos. Aparecida relata que, nesse momento, a mãe, ao perceber seu abatimento, a convocou para mergulhar na religião em definitivo, como um meio de 
sobrevivência. Nesse ponto, nota-se que Aparecida vivia um conflito entre o papel de matriarca da família, em que necessitava ser forte e objetivamente prover os recursos financeiros para o marido e o filho, e sua resistência - em função dos aspectos subjetivos, em especial as lembranças negativas - para retornar em definitivo para a religião.

Entendendo suas necessidades e com o aval da mãe, Aparecida alterou o rumo de sua vida, deixou as atividades como empreendedora e colocou uma placa em frente à sua casa com os dizeres: "Jogam-se cartas e búzios." Revelando sua nova identidade, a partir daquele momento passou a se chamar "Cidinha da Oiá". Logo em seguida, nos primeiros meses de trabalho, Cidinha conta, emocionada, que seus rendimentos possibilitaram pagar as despesas mensais da família. Com o passar dos anos, o trabalho proporcionou uma estabilidade econômica, como havia tempos não ocorria.

Hoje, após 3 décadas atuando como cartomante, a entrevistada acredita que atingiu a maturidade, que pode ser vista em seu próprio centro de religião e em sua extensa família religiosa, sinônimo de uma posição edificada dentro desse mercado. Ao projetar seu futuro, não visualiza alterações em sua trajetória profissional. O fato de ter o ofício como uma responsabilidade adquirida e destino de sua vida leva Cidinha a descartar outros caminhos e a prospectar sua permanência longeva nesse campo.

\section{Wesley, do Passado ao Presente}

Wesley nasceu em 1984, e suas primeiras memórias evocam as brincadeiras na escola. Diferentemente de seus colegas, sua diversão sempre continha traços religiosos. Enquanto os amigos desenhavam casas e animais durante as aulas e brincavam de esconde-esconde no recreio, Wesley pintava caboclos, tambores, e tentava recriar sessões de descarrego nos intervalos da aula. Esse comportamento fazia com que a escola chamasse regularmente seus pais para conversarem com o psicólogo ou com os pais de outros alunos que temiam suas brincadeiras. Alegava-se que Wesley não apresentava boas condições mentais, sendo considerado, em determinadas situações, um "encapetado", como ele destaca. Suas ações na infância são explicadas principalmente pela convivência com a avó, que havia anos trabalhava como batuqueira.

$\mathrm{Na}$ adolescência, o contato entre ele e o batuque cresceu. Wesley e a mãe, que nesse momento já havia mergulhado profissionalmente na religião, se mudaram e foram morar com a avó. Ele relata que "tudo que via na sessão de noite fazia durante a semana com meus colegas e amigos da rua". A convivência, a observação e a prática das atividades eram tão intensas que, logo aos 18 anos, Wesley detinha o domínio de grande parte dos processos de trabalho de um batuqueiro, além de já ter passado pela primeira experiência espiritual, incorporando a entidade "Pango Beira-Mar".

Depois da formatura no ensino médio, Wesley, incentivado pela mãe, buscou um emprego e um curso de graduação. Logo foi selecionado para trabalhar como assistente administrativo numa empresa, cargo que ocupou durante 5 anos. Ele conta também que iniciou o bacharelado em educação física, porém cursou apenas 3 disciplinas.

Ainda que tenha permanecido um tempo considerável em seu primeiro e único emprego, a ocupação e o curso noturno sempre entravam em conflito com as atividades religiosas. De acordo com os entrevistados, à medida que se apropria dos conhecimentos relativos à religião, assumem-se responsabilidades e atividades que precisam ser desempenhadas perante a família religiosa, o que demanda tempo e energia. Diante dessas exigências, o emprego e o curso de graduação sempre foram conflitantes com as atividades religiosas, que ocorriam especialmente durante a noite e as madrugadas, prejudicando a execução dos outros compromissos.

O embate entre atividades durou até o momento em que sua mãe de santo - nesse caso, sua avó - Ihe comunicou que ele estava preparado para exercer todas as atividades no mundo do batuque. A avó, que é a única pessoa que poderia Ihe designar tal papel, o tornou oficialmente um pai de santo. Nesse ponto, Wesley, que já não estava mais vinculado ao curso de graduação, também se desligou do emprego e começou a se dedicar integralmente aos atendimentos e às atividades religiosas.

Após quase uma década atuando como batuqueiro, o entrevistado relata que o trabalho ocupa integralmente o tempo de seu dia. Hoje, Wesley mora com a mãe, é separado há quase 11 anos e tem uma filha de 13 anos, que mora com sua antiga companheira. Ele conta que a menina, ainda que não tenha, em suas palavras, "despertado dentro da religião", vem criando raízes nesse mundo. 
Assim como seu passado e sua identidade, que mantiveram uma constância de integração junto ao batuque, todo o seu futuro é projetado nessa área. O desejo do entrevistado é, em primeiro lugar, o crescimento de sua família religiosa, aumentando o número de vínculos, e, em segundo, o desenvolvimento do centro de religião do qual ele e a mãe são proprietários. Isso, por meio do investimento de recursos no local, traria melhorias estruturais e atrairia um número maior de clientes ao espaço.

\section{DISCUSSÃO}

Em primeiro lugar, é importante dizer que, ao utilizar a estratégia investigativa da história de vida, as dinâmicas ocorridas entre indivíduo e contexto se mostram elementares, sobretudo em seu impacto na construção das carreiras. Os elementos tempo-espaço são peças importantes nessa análise (Abbott, 1997), bem como o confronto entre aspectos objetivos e subjetivos de diferentes gerações (Atkinson, 2002; Hughes, 1937).

A construção da carreira de mãe e filho contém aspectos semelhantes e outros marcadamente distintos, sobretudo em função dos diferentes períodos vividos e espaços vivenciados. Inicialmente, podemos destacar que os primeiros contatos com o campo religioso ocorreram de modo semelhante para ambos, porém as experiências foram significativamente contrárias. Em comum, mãe e filho nasceram em ambientes familiares religiosos, observando e adquirindo suas práticas. No entanto, enquanto Wesley enfrentou experiências negativas pontuais associadas às práticas religiosas, a exemplo de seu período na escola, Cidinha perpassou situações intensas, variadas e por longos períodos de tempo, como as duas décadas percorridas durante o regime militar.

Logo, percebe-se a produção de diferenças entre as trajetórias diante dos marcadores tempo-espaço social. O intervalo de quase 3 décadas entre suas infâncias e os espaços sociais em que foram criados - pequenas cidades no interior do Rio Grande do Sul, no caso de Cidinha, e numa metrópole como Porto Alegre, no caso de Wesley - agiram em tais caminhos.

O fato é que os contrastes contextuais iniciais projetaram a sequência percorrida pelos entrevistados (Mayrhofer et al., 2012). É possível dizer que as experiências iniciais de Wesley num espaço de menor conservadorismo e restrições, ao contrário do de sua mãe, não apresentaram tantas barreiras, permitindo-lhe maior poder de ação e ingresso no campo profissional da religião logo cedo, ao passo que sua mãe buscou outras experiências até adentrar a área.

Visto que o ambiente influencia as ações objetivas dos sujeitos dentro do campo, é possível perceber também as noções construídas a partir de eventos passados e que agora são compartilhadas pelos sujeitos entrevistados (Barley, 1989). Uma das subjetividades mais interessantes da análise é o sentimento de ingresso na ocupação da mãe em relação ao filho.

Nos relatos, Cidinha expôs que sua mãe, inicialmente, se mostrava convicta de seu desejo de ter a filha distante da religião, da mesma forma que ela apresentou certa insatisfação ao ver o filho seguindo seus passos posteriormente. Entretanto, nota-se um decréscimo na contrariedade de ingresso profissional na religião na relação entre mãe e filha e, posteriormente, entre mãe e filho. As construções sociais relativas à carreira em análise e às emoções próprias dos sujeitos apresentam uma transformação, pois estes mostram resistências menores ao ingresso profissional. Tal afirmação é reforçada quando Wesley, ao citar o futuro de sua filha, não apresenta nenhuma restrição às suas escolhas profissionais.

Sobre isso, podemos somar também a própria criação de uma nova identidade de Cidinha, que, diante de um tempo-espaço diferente, se permitiu adentrar uma carreira que poderia ter iniciado décadas antes. No momento da entrevista, embora seja possível ver que as lembranças foram desgastantes, notou-se uma reinterpretação do passado por parte Cidinha, amenizando tais fatos, na tentativa de deixar para trás significações da época. Nesses casos, conclui-se que as resistências e as significações, vistas sob o formato de noções construídas, nessa ordem, diminuíram e se transformaram em reflexo de um ambiente menos violento em relação ao exercício da ocupação.

É interessante observar também os status formados dentro desse conjunto social e que fazem parte da carreira religiosa. É comum encontrarmos uma série de denominações que rotulam as pessoas que trabalham em religiões afro-gaúchas, inclusive algumas criadas pelos próprios sujeitos com fins comerciais ou buscando se afastar da própria bagagem histórica de intolerância. Nomes como "cartomante", "tarólogo(a)", "astrólogo(a)", além de outros discriminatórios, como "saravá" e "macumbeiro", facilmente são vistos (Giorgio, 2015). Entretanto, ao contrário dessas terminologias, os entrevistados afirmam que, no grupo, são reconhecidos como "batuqueiros". 
É possível dizer ainda que o status de batuqueiro se divide de acordo com a posição exercida pelo indivíduo no grupo, podendo ser filho(a) de santo ou mãe/pai de santo. O primeiro enquadra os sujeitos que ingressaram nessa área e que podem se tornar, após um processo de treinamento, mães ou pais de santo. Já o segundo se refere a uma posição que permite ao indivíduo, de acordo com os preceitos internos do grupo, criar a própria família religiosa, capitanear as sessões em grupo e realizar atendimentos a seguidores e clientes.

O processo para adquirir esse status é interessante. Primeiro, os sujeitos precisam emergir na religião, aprendendo os elementos mitológicos, axiológicos, linguísticos e ritualísticos da vertente (Ramos, 2017). Depois, quem vai avaliar e conferir o título é o pai ou a mãe de santo. É possível, ainda, formalizar o título por meio das federações do grupo. No Rio Grande do Sul, com o aval do pai ou da mãe de santo do requerente, as federações podem emitir uma carteira de filiado, certificando o indivíduo como mãe/pai de santo e respaldando suas práticas de acordo com os direitos legais. As federações se amparam, sobretudo, na Constituição Federal de 1988, Artigo V, Parágrafo VI, que declara ser "inviolável a liberdade de consciência e de crença, sendo assegurado o livre exercício dos cultos religiosos e garantida, na forma da lei, a proteção aos locais de culto e a suas liturgias". Entretanto, os serviços religiosos oferecidos pelos batuqueiros, bem como de agentes de outras correntes religiosas, ainda não se enquadram em nenhuma jurisdição específica na esfera do trabalho (Constituição da República Federativa do Brasil, 1988).

Embora os entrevistados há tempos não renovem a carteira de filiado por meio do pagamento da anuidade, é através do movimento das federações que reside o principal vínculo entre eles e seus pares. Ambos revelaram que participam há quase dez anos, eventualmente, de movimentos em defesa das práticas afro-religiosas organizados pelas federações. Cidinha recorda que, "quando quiseram colocar a lei para não deixar matar os bichos, algo que é necessário para nós, fomos à frente da prefeitura, todos os batuqueiros, cantando e tocando tambor".

Com esse movimento, verifica-se que os indivíduos, principalmente por meio do somatório de forças, têm papel importante no sentido de agir sobre a estrutura do campo em que suas carreiras estão inseridas (Barley, 1989; Hughes, 1958). Nesse caso, a interferência direta pode ser vista em 2 momentos significativos. Primeiro, pelas decisões legislativas estaduais e, posteriormente, nacionais em favor do grupo, resultando numa legitimação social de suas práticas (Ministério Público Federal, 2018). Segundo, olhando para o passado não com a participação direta dos entrevistados, e sim pelo somatório de forças desse conjunto social, na criação de federações que lutam pelos direitos do grupo até hoje.

É possível perceber tal dinâmica ocorrida entre praticantes e demais instituições do campo desde o início da trajetória da carreira no batuque no Rio Grande do Sul. É esse processo histórico que explica o enquadramento da trajetória como uma carreira desviante. Ao olhar para trás, nota-se que a falta de legitimidade, somada a uma posição frágil de seus praticantes na sociedade, fez com que a violência e o preconceito sempre estivessem presentes no espaço dessa religião.

Os principais registros sobre a história dessa crença no Rio Grande do Sul até hoje são as páginas policiais (Oro, 2002). Atualmente, malgrado as práticas religiosas afro-gaúchas - sob a óptica da religião, e não do trabalho - estejam amparadas juridicamente e apoiadas por instituições associativas, seus praticantes ainda sofrem preconceito, sobretudo dos discursos intolerantes de religiões de raízes pentecostais (Guerreiro, 2018; Souza, 2019).

É a construção histórica desse cenário que contribui para afirmarmos que, tanto pelo viés do trabalho e da carreira quanto pela orientação religiosa, os entrevistados estão inseridos em subculturas ou subgrupos, o que os leva a serem considerados desviantes (Frigerio, 2008; Becker, 2008) - conceito internalizado e, de alguma forma, compreendido pelos respondentes a partir do momento que consideram anormais suas trajetórias na religião-trabalho.

Por fim, é inegável, de modo geral, a transformação do campo de carreiras religiosas afro-brasileiras diante do atual regime econômico e seu impacto na projeção futura dos profissionais. Primeiro, sob diversas formas, é possível ver como a noção de comércio vem adentrando práticas e processos desse campo. Já é possível encontrar pessoas que vendem, como um curso formatório, a preparação para se tornar pai de santo e pessoas que buscam a formação unicamente para atender clientes, visando apenas à esfera econômica do trabalho (Oro, 1998).

Por outro lado, verifica-se que até os entrevistados, criados sob crenças e práticas genuínas que envolvem a religião do batuque, não obstante hoje estejam longe de processos de racionalização definidos em suas atividades, já projetam como próximos passos dentro da carreira ações que visem ao desenvolvimento econômico de sua casa de religião ou, por outra perspectiva - já visualizando o alvorecer mercantil desse campo-, seu estabelecimento. 


\section{CONSIDERAÇÕES FINAIS}

Observando a relação tempo-espaço, suas transformações longitudinais, bem como as dinâmicas objetivas e subjetivas entre sujeito e contexto, este trabalho procurou investigar a carreira no batuque sob a narrativa de 2 pessoas de diferentes gerações que vivem essa trajetória. Ao resgatar a história da ocupação e dos sujeitos pesquisados, contextualizamos e interpretamos suas ações, assim como identificamos o papel de pessoas, grupos, organizações e sociedade nesse território.

Diante da discussão apresentada, é possível apontar mudanças transcorridas nessa carreira e obter elementos antecedentes, distintos, presentes e comuns aos sujeitos envolvidos, visualizando indícios de possíveis mudanças no campo do batuque. Sobre o primeiro apontamento, ao observar o caráter relacional proporcionado pelo conceito de carreira, ficam evidentes as dinâmicas ocorridas entre indivíduo, carreira e contexto. A pesquisa pôde identificar que, tanto na esfera do trabalho quanto em práticas e costumes ligados à religião, existem transformações oriundas principalmente do regime mercantilista. Da mesma forma, e seguindo nessa direção, as projeções futuras de carreira dos entrevistados cada vez mais se atrelam ao cenário econômico.

Sobre o segundo apontamento, podemos projetar que, embora o ambiente familiar indique ser um dos gatilhos para seguir essa trajetória ocupacional, o cenário econômico provoca, em nível estrutural no campo de carreiras, a inserção de novos atores. Entre eles, os grupos que mais se destacam são as pessoas que vendem e comercializam treinamentos e formações de pai/mãe de santo e o contingente que os busca. Dinâmicas que poderão influenciar as práticas daqueles já inseridos pela via da religião nesse mercado, talvez isso signifique maiores níveis concorrenciais entre casas/centros de religião e processos, hoje embrionários, profundos de racionalização nas práticas do grupo.

Considerando a carreira desviante, o olhar longitudinal para as representações (e suas transformações) dos entrevistados e o contexto experienciado permitiram observar a diminuição no número de barreiras encontradas na carreira do batuque ao longo dos anos, que nasceu num ambiente escravocrata, cruzou a ditadura militar e, hoje, enfrenta barreiras, sobretudo por meio de atos discriminatórios e preconceituosos, muitas vezes violentos e espraiados por múltiplos espaços. Além disso, o papel violento, antes praticado pelo Estado na figura das autoridades policiais, hoje pertence aos grupos religiosos neopentecostais intolerantes em suas crenças.

A conjuntura indica que, conquanto essa carreira tenha ganhado representatividade - por meio da criação das instituições representativas - e maior legitimidade nos últimos anos - pelas decisões legislativas favoráveis ao grupo e por ações públicas de incentivo à religião -, os sujeitos que a seguem ainda carregam rótulos que prejudicam suas atividades. Seus status são reconhecidos e valorizados apenas internamente no grupo. Externamente, o preconceito e a violência levam esses trabalhadores, muitas vezes, a acobertarem sua verdadeira identidade e assumir papéis diferentes na vida buscando maior flutuação entre ambientes. Isso nos permite dizer que essa carreira, além de desviante, se disfarça.

Por fim, investigando a ocupação de pessoas no batuque e explorando o ponto de vista daqueles que vivem esse mundo, o trabalho apresentou o campo dessa carreira, ampliou a discussão em áreas não tradicionais e ratificou o entendimento dela como uma sequência não linear e com (re)interpretações constantes de significados, assim como retratou as diferenças oriundas do tempo e do espaço, em instituições, grupos e indivíduos, com base na visualização da carreira de 2 pessoas de diferentes gerações que trilharam o mesmo caminho. 


\section{REFERÊNCIAS}

Abbott, A. (1997). Of time and space: The contemporary relevance of the Chicago School. Social forces, 75(4), 1149-1182. Recuperado de https://doi.org/10.2307/2580667

Arthur, M. B., Hall, D. T., \& Lawrence, B. S. (1989). Generating new directions in career theory: The case for a transdisciplinary approach. In M. B. Arthur, D. T. Hall, \& B. S. Lawrence (Eds.), Handbook of Career Theory (Cap. 1, pp. 7-25). Cambridge, UK: Cambridge University Press.

Atkinson, R. (2002). The Life Story Interview. In J. F. Gubrium, \& J. A. Holstein (Eds.), The Handbook of Interview Research: Context and Method (Cap. 6, pp. 121-141). London, UK: Sage.

Bardin, L. (2010). Análise de Conteúdo. Lisboa, Portugal: Edições 70.

Barley, S. R. (1989). Careers, identities, and institutions: the legacy of the Chicago School of Sociology. In M. B. Arthur, D. T. Hall, \& B. S. Lawrence (Eds.), Handbook of Career Theory (Cap. 3, pp. 41-65). Cambridge, UK: Cambridge University Press.

Becker, H. S. (2008). Outsiders: estudos de sociologia do desvio. Rio de Janeiro, RJ: Zahar.

Brandão, A. (2007). Entre a vida vivida e a vida contada: a história de vida como material primário de investigação sociológica. Configurações, 3, 83-106. Recuperado de http://hdl.handle.net/1822/9630

Bujold, C. (2004). Constructing career through narrative. Journal of vocational behavior, 64(3), 470-484. Recuperado de https://doi. org/10.1016/j.jvb.2003.12.010

Caregnato, R. C. A., \& Mutti, R. (2006). Pesquisa qualitativa: análise de discurso versus análise de conteúdo. Texto \& Contexto Enfermagem, 15(4), 679-684. Recuperado de https://doi.org/10.1590/ S0104-07072006000400017

Carter, M. J., \& Fuller, C. (2016). Symbols, meaning, and action: The past, present, and future of symbolic interactionism. Current Sociology, 64(6), 931-961. Recuperado de https://doi.org/10.1177/0011392116638396

Closs, L. Q., \& Rocha-de-Oliveira, S. (2015). História de vida e trajetórias profissionais: estudo com executivos brasileiros. Revista de Administração Contemporânea, 19(4), 525-543. Recuperado de https://doi.org/10.1590/1982-7849rac20151951

Colling, T., \& Oltramari, A. P. (2019). História de Vida e Teoria Interseccional. Revista ADM. MADE, 23(2), 59-69. Recuperado de http://dx.doi.org/10.21714/2237-51392019v23n2p059069

Constituição da República Federativa do Brasil de 1988. (1988). Brasília, DF. Recuperado de http://www.planalto.gov.br/ccivil_03/ constituicao/constituicao.htm

Corrêa, N. F. (1994). Panorama das religiões afro-brasileiras do Rio Grande do Sul. In A. P. Oro (Org.), As religiões afro-brasileiras do Rio Grande do Sul (Cap. 1, pp. 9-46). Porto Alegre, RS: Editora da UFRGS.

Corrêa, N. F. (2006). O batuque do Rio Grande do Sul: antropologia de uma religião afro-rio-grandense. Porto Alegre, RS: Cultura \& Arte.

DeLuca, G., \& Rocha-de-Oliveira, S. (2016). Inked careers: tattooing professional paths. BAR-Brazilian Administration Review, 13(4), e160081. Recuperado de https://doi.org/10.1590/1807-7692bar2016160081
Fernandes, M. E. (2010). História de vida: dos desafios de sua utilização. Revista Hospitalidade, 7(1), 15-31. Recuperado de https://www. revhosp.org/hospitalidade/article/view/292

Ferreira, J. P. (1959). Enciclopédia dos municípios brasileiros, 33. Rio de Janeiro, RJ: IBGE.

Frigerio, A. (2008). O paradigma da escolha racional: mercado regulado e pluralismo religioso. Tempo social, 20(2), 17-39. Recuperado de https://doi.org/10.1590/S0103-20702008000200002

Giorgio, R. P. D. (2015). Comércio de produtos religiosos em Porto Alegre: uma abordagem dos circuitos afro-brasileiro, esotérico e evangélico (Dissertação de Mestrado). Pontifícia Universidade Católica do Rio Grande do Sul, Porto Alegre, Brasil.

Granato, L., Lopes, F. T., \& Costa, A. D. S. M. D. (2020). Historia e investigación social cualitativa: reflexiones en torno de la historia comparada y la historia de vida. Organizações \& Sociedade, 27(94), 508-531. Recuperado de https://doi.org/10.1590/1984-9270946

Guerreiro, C. (2018). "Hoje à noite vai ter reteté, pô!”: evidências de conflitos cotidianos em rituais pentecostais. Debates do NER, 2(34), 123-154. Recuperado de https://doi.org/10.22456/1982-8136.89949

Hughes, E. C. (1937). Institutional office and the person. American journal of sociology, 43(3), 404-413. Recuperado de https://www. jstor.org/stable/2768627

Hughes, E. C. (1958). Men and their work. Chicago, IL: The University of Chicago Press.

Instituto Brasileiro de Geografia e Estatística. (2019). Cidades. Recuperado de https://cidades.ibge.gov.br/brasil/rs/pesquisa/23/22107

Leistner, R. (2016). Identidades, mediação institucional e modalidades de ação política no contexto das religiões afro-gaúchas. In M. Dillmann (Org.), Religiões e religiosidades no Rio Grande do Sul: matriz afro-brasileira (Cap. 5, pp. 113-140). São Paulo, SP: ANPUH.

Leite, R. F. (2017). A perspectiva da análise de conteúdo na pesquisa qualitativa: algumas considerações. Revista Pesquisa Qualitativa, 5(9), 539-551. Recuperado de https://editora.sepq.org.br/rpq/ article/view/129

Mariano, R. (2007). Pentecostais em ação: A demonização pentecostal dos cultos afro-brasileiros. In V. G. Silva. (Org.), Intolerância religiosa: impactos do neopentecostalismo no campo religioso afrobrasileiro (Cap. 3, pp. 119-148). São Paulo, SP: EDUSP.

Mayrhofer, W., Meyer, M., \& Steyrer, J. (2012). Contextual issues in the study of careers. In K. Inkson, \& M. L. Savickas (Eds.), Career Studies (Cap. 1, pp. 1-27). Thousand Oaks, CA: Sage Publications.

Ministério Público Federal. (2018). Procuradoria Federal dos Direitos do Cidadão (Nota Técnica). Recuperado de http://pfdc.pgr.mpf.mp.br/ atuacao-e-conteudos-de-apoio/publicacoes/livro-livre-exercicio-doscultos-e-liturgias-das-religioes-de-matriz-africana

Moore, C., Gunz, H., \& Hall, D. T. (2007). Tracing the historical roots of career theory in management and organization studies. In H. Gunz, \& M. Peiperl (Eds.), Handbook of career studies (Cap. 1, pp. 13-38). Thousand Oaks, CA: Sage Publications. 
Oliven, R. G. (2006). A parte e o todo: a diversidade cultural no BrasilNação. Petrópolis, RJ: Vozes.

Oro, A. P. (1998). Religião e Mercado no Cone Sul: as Religiões Afrobrasileiras como Negócio. In Anais da 22ㅇ Reunião Anual da Anpocs, Caxambu, MG.

Oro, A. P. (2002). Religiões afro-brasileiras do Rio Grande do Sul: passado e presente. Estudos afro-asiáticos, 24(2), 345-384. Recuperado de https://doi.org/10.1590/S0101-546X2002000200006

Oro, A. P. (2012). O atual campo afro-religioso gaúcho. CivitasRevista de Ciências Sociais, 12(3), 556-565. Recuperado de https:// doi.org/10.15448/1984-7289.2012.3.13015

Oro, A. P., Carvalho, E. T. D., \& Scuro, J. (2017). O sacrifício de animais nas religiões afro-brasileiras: uma polêmica recorrente no Rio Grande do Sul. Religião \& Sociedade, 37(2), 229-253. Recuperado de https:// doi.org/10.1590/0100-85872017v37n2cap09

Prandi, R. (1996). Religião paga, conversão e serviço. Novos Estudos, 45, 65-77. Recuperado de http://www.gpmina.ufma.br/ wp-content/uploads/2015/03/RELIGI\%C3\%83\%C6\%92O-PAGACONVERS\%C3\%83\%C6\%92O-E-SERVI\%C3\%83\%E2\%80\%A1O.pdf

Prefeitura Municipal de Porto Alegre. (2019). Secretaria Adjunta do Povo Negro. Plano Municipal de Promoção da Igualdade Racial.
Recuperado de http://www2.portoalegre.rs.gov.br/gpn/default. php?p_secao $=30$

Ramos, J. D. D. (2017, maio). Aprontamento como cosmopolítica: os corpos e seus outros na religião de Linha Cruzada. In Anais da 7o Reunião de Antropologia da Ciência e Tecnologia, Florianópolis, SC.

Silveira, H. A. A. N. (2014). Não somos filhos sem pais: história e teologia do batuque do Rio Grande do Sul (Dissertação de Mestrado). Faculdades EST, São Leopoldo, RS.

Souza, A. R. (2019). Pluralidade cristã e algumas questões do cenário religioso brasileiro. Revista USP, 120, 13-22. Recuperado de https:// doi.org/10.11606/issn.2316-9036.v0i120p13-22

Tadvald, M. (2016). O Batuque gaúcho: Notas sobre a história das religiões afro-brasileiras no extremo sul do Brasil. In: M. Dillmann (Org.). Religiões e religiosidades no Rio Grande do Sul: matriz afrobrasileira (Cap. 6, pp. 141-168). São Paulo, SP: ANPUH.

Vogt, S., \& Bulgacov, Y. L. M. (2019). História de vida de empreendedores: estratégia e método de pesquisa para estudar a aprendizagem empreendedora. Revista de Empreendedorismo e Gestão de Pequenas Empresas, 8(3), 99-133. Recuperado de https://doi.org/10.14211/ regepe.v8i3.1299

Alexandre Dal Molin Wissmann

ORCID: https://orcid.org/0000-0003-3965-336X

Doutorando em Administração do Programa de Pós-Graduação da Escola de Administração da Universidade Federal do Rio Grande do Sul (UFRGS).

E-mail: alewissmann@hotmail.com

Jhony Pereira Moraes

ORCID: https://orcid.org/0000-0002-1669-9181

Doutorando em Administração do Programa de Pós-Graduação da Escola de Administração da Universidade Federal do Rio Grande do Sul (UFRGS); Professor universitário no Centro Universitário FADERGS e na Faculdade Sistema de Ensino Gaúcho (FASEG). E-mail: jhonymoraes@hotmail.com.br

Arthur Gehrke Martins Andrade ORCID: https://orcid.org/0000-0002-1737-5138

Mestre em Administração pelo Programa de Pós-Graduação da Escola de Administração da Universidade Federal do Rio Grande do Sul (UFRGS) E-mail: arthur_gma@hotmail.com

Jair Jeremias Junior ORCID: https://orcid.org/0000-0002-4803-4125

Doutorando em Administração do Programa de Pós-Graduação da Escola de Administração da Universidade Federal do Rio Grande do Sul (UFRGS) E-mail: jair.jeremias.j@gmail.com 